\title{
NETWORKED PROFESSIONAL LEARNING: THE INFLUENCE ON UNIVERSITY TEACHERS' SELF- EFFICACY TO CREATE A POSITIVE UNIVERSITY CLIMATE
}

\author{
Oleksandr Malykhin \\ Institute of Pedagogy of the National Academy of Educational Sciences of Ukraine, Ukraine \\ Nataliia Aristova \\ Institute of Pedagogy of the National Academy of Educational Sciences of Ukraine, Ukraine \\ Nataliia Dyka \\ Kryvyi Rih State Pedagogical University, Ukraine
}

\begin{abstract}
The aim of this study is to evaluate the influence of networked professional learning on university teachers' self-efficacy to create a positive university climate. The study also provides, on the one hand, the theoretical overview of the scientific papers by Ukrainian and foreign scholars related to clarifying the understanding of the research leading concepts of "networked professional learning" and "informal learning" in scientific literature and, on the other hand, empirical research into the influence of networked professional learning on university teachers' self-efficacy to create a positive university climate. The experimental research was conducted in two stages. During the first stage of research a total of 267 university teachers who volunteered to participate in the research were interviewed for eliciting information concerning their participation activity rate in specially focused network pedagogical communities. During the second stage 108 university teachers selected from the total population by homogeneous sampling completed a questionnaire on teacher self-efficacy developed by A. Bandura. Although the findings of the study show that not all university teachers believe that there is a clear link between networked professional learning and high level of university teachers' self-efficacy, the majority of respondents recognize the increasing influence of informal learning in general and networked professional learning in particular on their professional growth. For understanding the research leading concepts and interpreting obtained findings methods of scientific literature analysis and mathematical statistics were used.
\end{abstract}

Keywords: networked professional learning; professional learning network; informal learning; university teacher; self-efficacy; teacher growth.

\section{Introduction}

The problem discussed in the article concerns the influence of networked professional learning on university teachers' self-efficacy to create a positive university climate. No matter how good initial teacher education is (OECD, 
2014), without lifelong learning teachers find it difficult to respond rapidly to constantly changing requirements for acquiring new teaching skills in the modern era of the Internet and information technologies. Although lifelong learning for teachers implies three forms, namely, formal, non-formal and informal learning, we are interested in the influence of the informal one on university teachers' growth and development of their self-efficacy. In this regard we consider networked professional learning as a kind of informal learning which is provided and shared by participants of professional learning networks.

Despite the fact that university teachers' active participation in professional learning networks promotes continuous professional growth and development of self-efficacy in creating a positive university climate, we believe that there are certain challenges which cannot be met by the majority of university teachers no matter how high the level of their self-efficacy is. These in most cases include the challenges caused by economic or political insecurity which affects deeply all residents of the country, creates unfavorable conditions for pursuing domestic higher education or vice-versa offers increasing possibilities for studying abroad.

Having considered all the views expressed by different scientists, we can assume that although active participation in various professional learning networks helps university teachers become more supportive with each other in creating positive university climate, there are some reasons to be skeptical.

The main objective of the study is to find out if professional learning networks influence the university teachers' self-efficacy to create a positive university climate and if there are certain situations in the workplace which are difficult to cope with despite their participation activity rate in professional learning networks. Two sub-objectives are formulated to reach the main objective: 1) to elicit information concerning the rate of university teachers' participation activity in professional learning networks; 2) to assess the influence of networked professional learning on university teachers' selfefficacy to create a positive university climate.

\section{Literature Review}

Many teachers who want to succeed in the teaching profession are notable for their aspiration to professional growth. In most cases it is expressed in the way they are ready to improve various on-the-job skills, gain new experience and share it with their colleagues and what is more important they are able to develop their self-efficacy. As a theoretical review of scientific literature indicates it is exactly self-efficacy which plays a very important role in thinking of yourself as an active agent of change in life and in the workplace (Bandura, 1977; Bandura, 1992; Bandura, 1993). As defined by A. Bandura (1977), 
self-efficacy is an individual's belief in his or her ability to complete a task in a specific situation, which affects the choice of activities, effort, and persistence of that individual. We fully agree that teachers whose self-efficacy is very high "tend to use more effective instructional practices, have greater enthusiasm for, and are more committed to teaching, and report greater job satisfaction” (OECD, 2014, p. 22). And teachers whose self-efficacy is low find it difficult to cope with students' misbehavior, to create positive atmosphere in the classroom to inspire confidence to students (OECD, 2014).

Following "Recognising Non-formal and Informal Learning: Pointers for policy development" (OECD, 2019), we believe that non-formal and informal learning regarded as types of learning that take place outside formal education institutions and can be a rich source of human capital. We do recognize nonformal and informal learning as being the ones that make human capital more visible and more valuable to society at large (OECD, 2019). Although informal learning unlike the formal one seems to be invisible and intangible at first sight, it is becoming more and more popular among university teachers. We are deeply convinced that in the era of increasing digitization of the world community it is informal learning that enables university teachers to strengthen their lifelong learning skills and become more efficient in the classroom.

Among various forms of informal learning professional learning networks might merit special consideration as they create a special environment or a so called "affinity space” (Krutka, Carpenter, \& Trust, 2016) where university teachers can construct new knowledge, deliberate on acute problems of mutual concern and propose reasonable solutions to them.

Participating in professional learning networks on a voluntary basis university teachers become more confident in handling any task as, on the one hand, they are provided with emotional support and encouragement by other members, and, on the other hand, they learn from other network members' experience. Thus, in our opinion, facing in one way or another mutual challenges in the working place, members of professional learning networks are likely to respond to them in the most effective way which is a result of collegial solidarity and support.

Although there are many different approaches to understanding and defining the concept of "professional learning network", no consensus has yet been reached. Thus, $\mathrm{H}$. Rheingold thinks that a professional learning network is a group of people linked by their participation in computer networks (1993). R. Flanigan explains that professional learning networks reduce isolation, promote autonomy, and provide inspiration by offering access to support and information around the globe (2011). According to T. Trust, D.G. Krutka and J.P. Carpenter professional learning networks are "uniquely personalized, complex systems of interactions consisting of people, resources, and digital tools 
that support ongoing learning and professional growth” (2016, p. 35). T. Trust thinks that "a professional learning network is a system of interpersonal connections and resources that support informal learning” (2012, p. 133). T. Trust distinguishes two types of professional learning networks, namely information aggregation and social media connections (2012). Information aggregation includes different RSS feeds and e-mail subscriptions whereas social media connections comprise social networking sites, affinity-based group sites and real-time interaction tools (2012). There is one more point of view according to which professional learning networks are divided into formally organized and informally developed ones (Lantz-Andersson, Lundin, \& Selwyn, 2018). As A. Lantz-Andersson, M. \& N. Selwyn (2018, p. 304) note, the distinction between mentioned professional learning networks relates only to the origin of their creation and initiation. Thus, formally organized professional learning networks are defined as top-down professional development endeavours, initiated by schools, districts and government agencies that usually function in accordance with predefined content and goals (Lantz-Andersson, Lundin, \& Selwyn, 2018, p. 304). Informally developed professional learning networks are regarded as bottom-up initiatives that involve like-minded colleagues who choose to come together to discuss, share information and work together (Lantz-Andersson, Lundin, \& Selwyn, 2018). Therefore professional learning networks either formally organized or informally developed help their members meet diverse social, cognitive, affective and identity needs through sharing and generating content, providing and receiving mentoring and creating diverse forms of knowledge (Krutka, Carpenter, \& Trust, 2016). A literature review shows that professional learning networks, in most cases, serve as a source of collegial support, emotional engagement and reflection, sharing and filtering new ideas (Lantz-Andersson, Lundin, \& Selwyn, 2018). While noting A. Lantz-Andersson, M. Lundin \& N. Selwyn's point of view on classification of professional learning networks, we believe that as a result of intensified computerization of all areas of human activities functioning of formally organized and informally developed professional learning networks might imply the combination of face-to-face and online communication and sharing of information (2018).

\section{Research Methodology}

The study was carried out in the 2017/2018 academic year among the university teachers of seven higher educational institutions. These universities were National University of Life and Environmental Sciences of Ukraine (Kyiv), National Technical University of Ukraine «Igor Sikorsky Kyiv Polytechnic Institute» (Kyiv), Ivan Franko National University of Lviv (Lviv), 
National Aviation University (Kyiv), Ternopil Volodymyr Hnatiuk National Pedagogical University (Ternopil), Donetsk National University of Economics and Trade named after Mykhailo Tugan-Baranovsky (Kryvyi Rih), Kryvyi Rih State Pedagogical University (Kryvyi Rih).

To meet the first sub-objective 267 university teachers were selected by convenience sampling. The following research questions were posed:

Question 1: Are you a member of any professional learning network? In case your answer is negative explain why. If the answer is positive continue answering questions.

Question 2: What kind of member are you?

Question 3: Do you believe that participation in professional learning networks improves your self-efficacy to create a positive university climate?

To meet the second sub-objective 108 university teachers were selected from the total population by homogeneous sampling based on the rate of respondents' participation activity in professional learning networks. Such a distribution of university teachers into three groups, namely active members, non-regular members and non-members professional learning networks, was substantiated in the research by N. Malykhin and O. Aristova (2018).

Data collection instrument comprised the questionnaire on teacher selfefficacy, which we adapted to evaluate university teachers' self-efficacy to create a positive university climate (Bandura, 2006). The choice of A. Bandura's questionnaire on teacher self-efficacy is due to the fact that among a large number of questionnaires developed for evaluating self-efficacy (Schwarzer \& Jerusalem, 1995; Panc, Mihalcea, \& Panc, 2012; Gaumer Erickson \& Noonan, 2018) it seems to be the most relevant for evaluating university teachers' selfefficacy to create a positive university climate. The Self-Efficacy Survey developed by T. Panc, M. Mihalcea, \& I. Panc (2012) assists in evaluating ten functional areas of life, namely, intellectual, family, educational, professional, social, religious, erotic, moral, life standard and health. The use of the selfefficacy formative questionnaire by A.S. Gaumer Erickson \& P.M. Noonan (2018) makes it possible to assess the belief in personal ability and the belief that ability grows with effort. The questionnaire designed by R. Schwarzer \& M. Jerusalem (1995) makes it possible to assess a general sense of perceived self-efficacy.

Having interviewed 267 university teachers from seven universities (National University of Life and Environmental Sciences of Ukraine (Kyiv), National Technical University of Ukraine «Igor Sikorsky Kyiv Polytechnic Institute» (Kyiv), Ivan Franko National University of Lviv (Lviv), National Aviation University (Kyiv), Ternopil Volodymyr Hnatiuk National Pedagogical University (Ternopil), Donetsk National University of Economics and Trade named after Mykhailo Tugan-Baranovsky (Kryvyi Rih), Kryvyi Rih State 
Pedagogical University (Kryvyi Rih)), we have found that university teachers are concerned about the same problems. The greatest concerns expressed by respondents are about increased students' absenteeism and dropout, teachers' inability to make students enjoy coming to university and believe they can improve their academic performance, lack of understanding among university teachers and the administration on some thorny questions etc. Bearing in mind the results of the interview, A. Bandura's questionnaire on teacher self-efficacy (2006) is considered a valid tool for meeting the second sub-objective of the research. Thus, for evaluating university teachers' self-efficacy to create a positive university climate, university teachers were asked to rate 8 statements by recording a number from 0 to 100: 1) make the university the safe place; 2) make students enjoy coming to university; 3) get students to trust teachers; 4) help other teachers with their teaching skills; 5) increase collaboration between teachers and the administration to make the university run effectively; 6) reduce university dropout; 7) reduce university absenteeism; 8) get students to believe they can do well in university work.

Then, the obtained data were analyzed quantitavely.

\section{Results and Discussion}

The first research sub-objective was to elicit information concerning the rate of university teachers' participation activity in professional learning networks. A total of 267 university teachers were selected using convenience sampling for eliciting information concerning the rate of university teachers' participation activity in professional learning networks. The results are presented in Table 1.

Table 1 Distribution of respondents concerning the rate of their participation activity in professional learning networks

\begin{tabular}{|l|c|c|}
\hline \multirow{2}{*}{ Participation activity } & \multicolumn{2}{|c|}{$\begin{array}{c}\text { Distribution of respondents } \\
\text { (267 university teachers) }\end{array}$} \\
\cline { 2 - 3 } & $\mathbf{N}$ & $\mathbf{\%}$ \\
\hline Non-members & 89 & 33.33 \\
\hline Non-regular members & 126 & 47.19 \\
\hline Active members & 52 & 19.48 \\
\hline
\end{tabular}

Source: own study

$N=267$

The obtained results show that only $19.48 \%$ of respondents are active members, $33.33 \%$ are non-members and $47.19 \%$ are non-regular members of professional learning networks. Besides, the data gathered through the interviews enable us to say with confidence that the views of respondents on 
being or not being a part of a professional learning network within each group are rather similar. Thus, university teachers identifying themselves as nonmembers of professional learning networks believe that it is impossible to have any experience gained only by communicating with colleagues and sharing useful information ( $\mathrm{n}=89$; 33.33\%). Moreover, non-members of professional learning networks are convinced that new skills and knowledge that improve their work performance can be gained only doing courses of continuing training organized by state educational establishments. They regard participation in professional learning networks as a complete waste of time mentioning that they can interact with their colleagues at department meetings. Also, it is worth noting that all 89 respondents representing non-members of professional learning networks think that some specific situations which arise during the academic year cannot be influenced neither by university teachers themselves nor by administration itself. In their point of view, the respondents' responses range from university absenteeism caused by the urgent need to earn money to pay for their studies to some manifestations of violence which might be carried out by outsiders as a result of insecure domestic political situation.

Besides, respondents $(n=89 ; 33.33 \%)$ who regard themselves as nonmembers of professional learning networks recognize the fact that they even avoid participating in routine events of formally organized professional learning networks that function at their higher educational institutions, for example:

"I see no reason for attending the routine meetings as they impose the interests of university administration and do not take into consideration the interests of all university faculty members. Moreover, in most cases they usually have a very formal character and we have no opportunity to discuss the things we are interested in. Therefore we prefer not to express our personal points of view during such meetings but only listen to information we need to know". (Tetyana)

$47.19 \%(n=126)$ of respondents who see themselves as non-regular members point out that although they admit the numerous advantages of participating in professional learning networks they are not fully engaged in all events offered by them. They see more advantages in communicating online as in this case the communication has more virtual nature and network members are not obliged to discuss or do something they do not like:

"I do not consider myself as an active member of any professional learning network. I am more a non-regular member as I join the network events only when I need to get some information or I vice versa I know something interesting which is worth sharing etc. And although I am a member of one professional learning network informally developed by my colleagues and formally organized by university administration, I am not ready to waste all my time on the improvement of my professional skills. I prefer to be a part of professional learning networks which provide more services, activities and discussions online and keep a face-to-face interaction to a minimum. In this case you can join a discussion, attend a meeting or a seminar only when you are interested in the topic. You know the topics which are discussed in a group beforehand and if you do not know anything you have much time to find 
some interesting materials to share. With regard to face-to-face meetings, I am not shy but to tell the truth sometimes I don't want to express my personal point of view in public. Besides, when my colleagues discuss issues which are not within my sphere of competence I am afraid to look stupid in front of them”. (Olena)

As the obtained results show $19.48 \%$ of respondents $(n=52)$ are active members of professional learning networks. It means that they not only take part in all types of activities provided by network administrators but initiate discussions, organize activities and try to share useful information among network members themselves. Advantages listed by all 52 respondents include joint discussions, information and networking, provision of resources for teaching the students, opportunity to reveal your potential and share your unique experience with other network members, practical and emotional support etc. We have to note that we are also profoundly convinced that joint discussions aimed at finding deliberate solutions help university teachers increase their selfefficacy which along with the development of soft and hard skills influence their professional growth. In the majority of cases, the replies of respondents who represented the active members of professional learning networks were as follows:

"Sometimes you do not know what to do even if you have great work experience. In this case join discussions help us find the appropriate solutions. We all know that together we can “move mountains". It doesn't necessarily mean that you will be explained everything you do not know immediately during the meeting. If you tell about you problems your colleagues definitely help you to tackle them sharing their own experience. And you can understand that it is in our reach to change our life for better. I adore when we meet because each new discussion is an unforgettable experience full of various emotions. But, to tell the truth, faceto-face meetings take much time which you do not often have. In this case professional learning networks which combine their face-to-face activities with activities provided online give you a complete freedom of choice in communicating with each other and sharing new ideas. Participating in online discussions we share our own experiences and useful information for members of a professional learning network you take part in without leaving your home or workplace." (Nataliia)

Interview results mentioned above offered the opportunity for us to get the necessary information which was further used for the distribution of respondents selected from the total population by homogeneous sampling. The results are given in Table 2.

Table 2 Distribution of respondents for evaluating the influence of networked professional learning on university teachers' self-efficacy to create a positive university climate

\begin{tabular}{|l|l|}
\hline Participation activity & N \\
\hline Non-members & 36 \\
\hline Non-regular members & 36 \\
\hline Active members & 36 \\
\hline
\end{tabular}

Source: own study

$n=108$ 
SOCIETY. INTEGRATION. EDUCATION

Proceedings of the International Scientific Conference. Volume V, May $22^{\text {th }}-23^{\text {th }}$, 2020. 200-212

We conducted the research to find out if professional learning networks influence the university teachers' self-efficacy to create a positive university climate. We also were interested if there were certain situations in the workplace which were difficult to cope with despite their participation activity rate in professional learning networks. Table 3 presents the obtained results.

Table 3 University teachers' self-efficacy levels to create a positive university climate

\begin{tabular}{|c|c|c|c|c|}
\hline \multirow{2}{*}{ Sub-categories } & \multirow{2}{*}{$\begin{array}{c}\text { Respondents' } \\
\text { participation activity in } \\
\text { professional learning } \\
\text { networks (N) }\end{array}$} & \multicolumn{3}{|c|}{$\begin{array}{c}\text { Respondents' degree of } \\
\text { confidence }\end{array}$} \\
\hline & & $\begin{array}{c}\text { Low } \\
(\mathrm{N})\end{array}$ & $\begin{array}{l}\text { Medium } \\
\text { (N) }\end{array}$ & $\begin{array}{l}\text { High } \\
\text { (N) }\end{array}$ \\
\hline \multirow{3}{*}{$\begin{array}{l}\text { Efficacy to make the university } \\
\text { a safe place }\end{array}$} & Non-members (36) & 25 & 10 & 1 \\
\hline & Non-regular members (36) & 22 & 12 & 2 \\
\hline & Active members (36) & 23 & 13 & 0 \\
\hline \multirow{3}{*}{$\begin{array}{l}\text { Efficacy to make students } \\
\text { enjoy coming to university }\end{array}$} & Non-members (36) & 18 & 18 & 0 \\
\hline & Non-regular members (36) & 12 & 19 & 5 \\
\hline & Active members (36) & 3 & 23 & 10 \\
\hline \multirow{3}{*}{$\begin{array}{l}\text { Efficacy to get students to trust } \\
\text { teachers }\end{array}$} & Non-members (36) & 24 & 11 & 1 \\
\hline & Non-regular members (36) & 13 & 16 & 7 \\
\hline & Active members (36) & 3 & 24 & 9 \\
\hline \multirow{3}{*}{$\begin{array}{l}\text { Efficacy to help other teachers } \\
\text { with their teaching skills }\end{array}$} & Non-members (36) & 18 & 18 & 0 \\
\hline & Non-regular members (36) & 10 & 20 & 6 \\
\hline & Active members (36) & 5 & 18 & 13 \\
\hline \multirow{3}{*}{$\begin{array}{l}\text { Efficacy to increase } \\
\text { collaboration between teachers } \\
\text { and the administration to make } \\
\text { the university run effectively }\end{array}$} & Non-members (36) & 18 & 18 & 0 \\
\hline & Non-regular members (36) & 16 & 17 & 3 \\
\hline & Active members (36) & 4 & 20 & 12 \\
\hline \multirow{3}{*}{$\begin{array}{l}\text { Efficacy to reduce university } \\
\text { dropout }\end{array}$} & Non-members (36) & 22 & 14 & 0 \\
\hline & Non-regular members (36) & 18 & 18 & 0 \\
\hline & Active members (36) & 21 & 15 & 0 \\
\hline \multirow{3}{*}{$\begin{array}{l}\text { Efficacy to reduce university } \\
\text { absenteeism }\end{array}$} & Non-members (36) & 21 & 15 & 0 \\
\hline & Non-regular members (36) & 18 & 18 & 0 \\
\hline & Active members (36) & 20 & 16 & 0 \\
\hline \multirow{3}{*}{$\begin{array}{l}\text { Efficacy to get students to } \\
\text { believe they can do well in } \\
\text { university work }\end{array}$} & Non-members (36) & 24 & 11 & 1 \\
\hline & Non-regular members (36) & 11 & 19 & 6 \\
\hline & Active members (36) & 1 & 26 & 9 \\
\hline
\end{tabular}

Source: own study

$n=108$

While analyzing the findings of the research, we found out some interesting key traits which are shared by all respondents despite the rate of their participation activity in professional learning networks. The results show that there are some situations teachers have little influence on (Table 3). Most university teachers find it difficult to make the university a safe place, reduce 
university dropout and university absenteeism. Thus, $0 \%$ of the active members, $6 \%$ of the non-regular members and $3 \%$ of non-members of professional learning networks demonstrate high level of self-efficacy to make the university a safe place. A medium level of self-efficacy to make the university a safe place is demonstrated by $36 \%$ of the active members, $33 \%$ of the non-regular members and $28 \%$ of non-members of professional learning networks. $64 \%$ of the active members, $61 \%$ of the non-regular members and $69 \%$ of non-members of professional learning networks think that they have a low self-efficacy to demonstrate their competence in making university a safe place.

All respondents mentioned that it was their top priority to make university a safe place but they could not guarantee that all other people shared the same point of view. The second idea respondents noted was that it was the main responsibility of university administration to ensure the safety of teachers and students.

$0 \%$ of the active members, the non-regular members and non-members of professional learning networks shows a high level of self-efficacy to reduce university absenteeism and university dropout. $45 \%$ of the active members, $50 \%$ of the non-regular members and $42 \%$ of the non-members of professional learning networks demonstrate a medium level of self-efficacy to reduce university absenteeism. Based on the results of research, 15 active members (42\%), 18 non-regular members (50\%) and 14 non-members (39\%) of professional learning network demonstrate a medium level of self-efficacy to reduce university dropout. 20 active members (55\%), 18 non-regular members (50\%) and 21 non-members (58\%) of professional learning networks show a low level of self-efficacy to reduce university absenteeism. The results concerning the low level self-efficacy to reduce university dropout are approximately the same. Thus, 21 active members (58\%), 18 non-regular members (50\%) and 22 non-members (61\%) of professional learning networks think that their level of self-efficacy to reduce university absenteeism is low.

Pointing out that they cannot influence students' absenteeism and as a result their dropout, university teachers explain:

"There are students who attend their classes according to their individual schedule. They really try very hard to do all the tasks on time but sometimes they fail. On the one hand, I don't think I have the right to ask them to give up their work understanding that no one helps them pay for tuition. But on the other hand, I think they lose their opportunity to learn all the necessary skills and, moreover, as my own experience shows absenteeism often causes dropout". (Iryna)

The findings of research show that the non-regular and active members of professional learning networks are more efficient in making students enjoy coming to university, getting students to trust teachers and to believe they can do well in university work than non-members. Thus, 10 active members (28\%) and 5 non-regular members (14\%) demonstrate a high level of self-efficacy to make 
students enjoy coming to university. A high level of self-efficacy to get students to trust teachers is shown by $25 \%$ of active members, $19 \%$ of non-regular members and $3 \%$ of non-members of professional learning networks. Concerning the self-efficacy to get students to believe they can do well in university work, a high level is demonstrated by $25 \%$ of active members, $17 \%$ of non-regular members and 3\% of non-members of professional learning networks.

The results of data analysis demonstrate that active members of professional learning networks are more efficient in helping other teachers with their teaching skills and increasing collaboration between teachers and the administration to make the university run effectively than non-regular members and non-members. Thus, a high level of self-efficacy to help other teachers with their teaching skills is shown by $36 \%$ of active members and $17 \%$ of non-regular members of professional learning networks. Non-members do not demonstrate a high level of self-efficacy to help other teachers with their teaching skills. 18 active members (50\%), 20 non-regular members (55\%) and 18 non-members (50\%) of professional learning networks show a medium level of self-efficacy to help other teachers with their teaching skills. The percentage of active members of professional learning networks with a low level of self-efficacy to help other teachers with their teaching skills is $14 \%$ and of non-regular members is $28 \%$. At the same time $50 \%$ of non-members of professional learning networks demonstrate a low level of self-efficacy to help other teachers with their teaching skills.

Evaluating their level of self-efficacy to help other teachers with their teaching skills, active members of professional learning networks note:

"When I started teaching I often spent much time on finding new engaging printables I could use during my classes. And after long search, to tell the truth, I was not ready to share my experience with anyone. One of my colleagues added me to one of professional learning networks she was an active member. I was surprised to know that people were ready to help and did not wait anything in return. Now I am an active member of several professional learning networks and thanks to participation in them I don't have to spend vast effort on attempts to find something unusual. I can simply ask my colleagues to help me and help them with pleasure. We share not only creative ideas but task cards to help students practice necessary skills, printables, various activities with instructions, ready-to-use lessons and even some materials to sharpen our skills". (Olha)

A high level of self-efficacy to increase collaboration between teachers and the administration to make the university run effectively is demonstrated by $33 \%$ of active members and $8 \%$ of non-regular members of professional learning networks. And a low level is shown by $50 \%$ of non-members, $45 \%$ of non-regular members and only $12 \%$ of active members of professional learning networks. Evaluating this sub-category, the majority of active members and nonregular members of professional learning networks mention: 
"I am a member of the professional learning network which was organized at out university and its members are not only lecturers but the university administration itself. Although we have the opportunity to discuss acute problems we are not often on the same side of every issue. They say "Truth can spark when opposing ideas collide" which I think is true. Discussion often helps us identify how best to address new challenges we face in our everyday work". (Lyudmyla)

Thus, the analysis of obtained results shows that the respondents who are active members of professional learning networks are better able to create a positive university climate.

\section{Conclusions and Prospects for Further Research}

The primary objective of the study was to find out if professional learning networks influence the university teachers' self-efficacy to create a positive university climate and if there were certain situations in the workplace which were difficult to cope with. The findings of the research support our assumption that despite the fact that university teachers' active participation in professional learning networks promotes continuous professional growth and formation of self-efficacy in creating positive university climate, there are certain challenges which cannot be met by the majority of university teachers no matter how high the level of their self-efficacy is. Thus, finding it difficult to make the university a safe place, reduce university dropout and university absenteeism, nonmembers, non-regular members and active members of professional learning networks connect their inefficiency more with economic or political insecurity in the country, inability to put it an end and students' search for a better life. At the same time the results of research make it possible to state that people who can create supportive atmosphere for colleagues and help them improve their self-esteem can teach their students to trust teachers, make them enjoy coming to university, help other teachers with their teaching skills and increase collaboration between teachers and university administration.

Further research concerning the influence of professional learning networks on the improvement of university teachers' agentic qualities should be noticed more deeply.

\section{References}

Bandura, A. (1992). Exercise of personal agency through the self-efficacy mechanisms. In R. Schwarzer (Ed.), Self-efficacy: Thought control of action (pp. 3-38). Washington, DC: Hemisphere.

Bandura, A. (2006). Guide for Constructing Self-Efficacy Scales. In F. Pajares and T. Urdan (Eds.), Self-Efficacy Beliefs of Adolescents, (Vol. 5, pp. 307-337). Greenwich: Information Age Publishing. 
Bandura, A. (1993). Perceived self-efficacy in cognitive development and functioning. Educational Psychologist, 28, 117-148.

Bandura, A. (1977). Self-efficacy: Toward a Unifying Theory of Behavioral Change. Psychological Review, 84(2), 191-215.

Flanigan, R. (2011). Professional learning networks taking off. Education Week, 2011. Retrieved from http://www.edweek.org/ew/articles/2011/10/26/09edtech-network.h31. html?tkn=NXCFrTi53Q/RNUP7oI3Dyieu/9gskTJyoOc/

Gaumer Erickson, A.S., \& Noonan, P.M. (2018). Self-efficacy formative questionnaire. In The skills that matter: Teaching interpersonal and intrapersonal competencies in any classroom (175-176). Thousand Oaks, CA: Corwin.

Krutka, D.G., Carpenter, J.P., \& Trust, T. (2016). Elements of Engagement: A model of Teacher Interactions via professional learning networks. Journal of Digital Learning in Teacher Education, 32(4), 150-158.

Lantz-Andersson, A., Lundin, M., \& Selwyn, N. (2018). Twenty years of online teacher communities: A systematic review of formally-organized and informally developed professional learning groups. Teacher and Teacher Education, 75, 302-315. Retrieved $26^{\text {th }}$ of October 2018, from https://www.researchgate.net/publication/326478602 Twenty_years_of_online_teacher_communities_A_systematic_review_of_formallyorganized_and_informally-developed_professional_learning_groups

Malykhin, O., \& Aristova, N. (2018). Investigation into participation activity rate of foreign languages teachers in specially focused network pedagogical communities. The New Pedagogical Review, 53(3), 227-238.

OECD. (2014). A teacher's Guide to TALIS 2013: Teaching and Learning International Survey, TALIS, OECD publishing. Retrieved from https://read.oecd-ilibrary.org/ education/a-teachers-guide-to-talis-2013_9789264216075-en\#page4: https://read.oecdilibrary.org/education/a-teachers-guide-to-talis-2013_9789264216075-en\#page4

OECD. (2019). Recognising Non-formal and Informal Learning: Pointers for policy development, March 2010. [Online]. Retrieved from file://C:/Users/Asus/Desktop/nonformal\%20and\%20formal\%20learning.pdf_[Accessed: Dec. 22, 2018].

Panc, T., Mihalcea, A., \& Panc, I. (2012). Self-efficacy survey: a new assessment tool. Social and Behavioral Sciences, vol. 33, 880-884. Retrieved from https://www.sciencedirect. com/science/article/pii/S187704281200256X

Rheingold, H. (1993). The Virtual Community: Homesteading on the Electronic Frontier. Reading, MA: Addison-Wesley.

Schwarzer, R., \& Jerusalem, M. (1995). Generalized Self-Efficacy scale. In J. Weinman, S. Wright, \& M. Johnston, Measures in health psychology: A user's portfolio. Causal and control beliefs (pp. 35-37). Windsor, England: NFER-Nelson.

Trust, T. (2012). Professional learning networks designed for teacher learning. Journal of Digital Learning in Teacher Education, 28(4), 133-138.

Trust, T., Krutka, D.G., \& Carpenter, J.P. (2016). Together We Are Better”: Professional Learning Networks for Teachers, Computers \& Education. Retrieved from http://www.sciencedirect.com/science/article/pii/S036013151630135X DOI: 10.1016/j. compedu.2016.06.007 